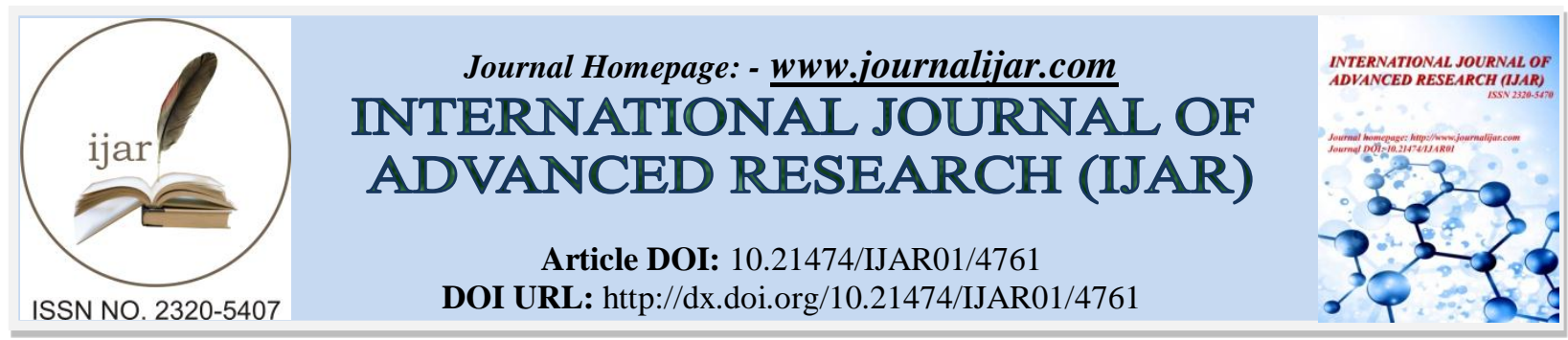

RESEARCH ARTICLE

\title{
ESTIMATES OF MULTI-COLLINEARITY FOR SUPPLY FUNCTION OF PORK BY TIME-SERIES DATA IN SOUTH KOREA.
}

\author{
Tae Wan Kim. \\ Swine Science and Technology Center, Gyeongnam National University of Science \& Technology, Jinju 52725, \\ South Korea.
}

\section{Manuscript Info}

Manuscript History

Received: 6 May 2017

Final Accepted: 8 June 2017

Published: July 2017

Key words:-

Producer \& distributor, $6^{\text {th }}$ industrialization, management, decisionmaking, entrepreneur, market equilibrium.

\begin{abstract}
A large amount of pork has been imported in South Korea according to conclusion of FTA with many countries. Therefore, analysis on determinants in production of domestic pork (PDP) plays a critical role as an indicator for decision making of producer and distributor of pork. As a result of this study, the independent variables to explain PDP were selected by 7 and 4 variables through variance inflation factor and stepwise selection method, respectively. The consumption of domestic pork and beginning stocks of domestic pork played an important role to determine PDP $(\mathrm{P}<0.01)$. In addition, Hanwoo beef and chicken, which is recognized as an alternative to pork, were a weak but played a role as a substitute material. However, Pork in South Korea to clearly maintain four seasons exhibited seasonally contradictory characteristics due to supply quantity depending on biological characteristics and specific consumption culture. Therefore, we suggest that producer and distributor are economically important to control marketing volume in response to biological characteristics of pig, and seasonal demand and supply situations of pork market. In other words, it is necessary that producer and distributor carry out rearing and inventory managements, respectively, to supply the summer market increasing consumption.
\end{abstract}

Copy Right, IJAR, 2017,. All rights reserved.

\section{Introduction:-}

In general, it is difficult to measure economic development situation from result of country's agricultural trade balance. While trade deficit in agricultural sector has been increased in South Korea, high economic growth and increase in food consumption have been carried out together. Otherwise, agriculture in many emerging economies is gradually changing to commercialize high-value added foods such as chicken, pork and fish (FAO 2014). Much of growth in meat production is concentrated in countries experienced by rapid economic growth and revolved around poultry and pig. Although production and consumption of livestock products have been reached at a high level in developed countries, those are currently growing only slowly or stagnating (Thornton 2010). Pork is one of the most widely consuming meats in the world. According to FAO statistics at 2014, pig production in the world is realized in $1,466,760,933$ heads. The most important share in production of pig belongs to China (48.05\%), USA (6.86), Brazil and Germany $(2.87 \%)$, but South Korea $(1.02 \%)$ is $16^{\text {th }}$ production nation of pig (FAOSTAT 2016).

Consumption of pork is steadily increasing according to improvement in national income in South Korea. On the basis of the increased consumption, as production of pork has also been increased, it has been recently gained 
attention as the most important item of agricultural production. Although increase in production and consumption of pork had been led to startup of the related industries, it presents rate of increased failure. Startup's failure is caused by production and supply of unnecessary products and services in market by producing and supplying products and services to want startup himself without a thorough analysis of consumers. Along with this phenomenon, high sets of price when compared to appropriate price expected by consumers are pointed out as a factor to increase failure rate of establishment (CB insights 2014). Therefore, it is very important to satisfy quality and price required by consumers for success of establishment in pork market. However, it is important for producer and distributor of pork to understand specificity of supply and demand traded on market more than anything and to make its excellent application.

This study is to evaluate the determinants of domestic pork supply by multiple regression model, which it is the important indicators for decision-making of the producer, distributor and consumer related to supply and demand of pork market in South Korea. However, there is a high possibility that multiple collinearity exists between factors to determine supply amount of pork. Therefore, we analyzed factors to significantly affect behavior of PDP by variance inflation factor (VIF) and stepwise selection method (STEPWISE).

\section{Materials and Methods:- \\ Data collection:-}

Commodities generally distributed in a market are closely related to various factors in supply and demand sectors (Kim 2016a), and consumption of pork are also determined by influence of various factors. In this study, to evaluate factors determining production of pork, we employed various secondary data reported from Korean Statistical Information Service (KOSIS), National Agricultural Cooperative Federation (NACF) and Korea Meat Trade Association (KMTA). All the data were monthly collected from January 2003 to October 2016 (166 months). Since nominal prices of pork and related goods were changed by various values in each year instead of equalizing real value, the employed price data were presented by the real prices based on the consumer price index (CPI) 2010 $(2010=100)$. Moreover, dependent variable was measured in quantity, which is not affected by inflation (Lam et al. 2013). Thus, prices of pork and the related goods used in this study were indicated by real price.

As shown in Table 1, we examined variables related to domestic pork production function. The transaction of goods in the market determines market price, production amount and consumption amount by interaction of elements contained in demand and supply functions. Here, since population age 15 years or older (PA15) represented scales of consumers, and Hanwoo beef and chicken recognized as an alternative to pork, we selected their prices as variables. Since feed expenditure accounted for approximately 54\% of domestic pig production expenditure, and recognized as the most important production factor in pig production, it was included in variable. In addition, as livestock market was intensified in competition among countries such as imported pork exchanging domestic pork due to trade liberalization, the export and import volumes of pork were selected to determinant factor for production of domestic pork.

\section{Data analysis:-}

Mathematical model to analyze factors affecting production of domestic pork was done by multiple linear regression analysis. Production of domestic pork to employ supply function was described as below:

$Y=\beta_{0}+\beta_{1} X_{1}+\beta_{2} X_{2}+\cdots+\beta_{p} X_{p}+\varepsilon_{i}$

Where

$\beta_{0} \cdots \beta_{p}$ are coefficients for predictor variables $X_{1} \cdots X_{p}$, and $\varepsilon_{i}$ represents error term. If expected value is 0 , variance has $\sigma^{2}$.

$H_{0}: \beta_{j}=0$ Vs $H_{1}: \beta_{j} \neq 0, j=0,1,2, \cdots, p$. If null hypothesis $\left(H_{0}\right)$ is rejected at significant level $\alpha$, the alternative hypothesis $\left(H_{1}\right)$ is adopted. At least one or more among independent variable $\left(X_{1}, X_{2}, \cdots, X_{p}\right)$ indicate contributions to regression model. Verification of model uses analysis of variance (ANOVA). At that time, statistic for test of null hypothesis is $F_{0}=S S R / p / S S E /(n-p-1)=M S R / M S E$. In here, $S S R$ is sum of the squares of

residuals in the model, $S S E$ is sum of errors in the squares, the mean square for error $(M S R)$ is the mean squared residuals, and MSE indicates the mean-squared error in the estimator (SAS 2009). If the null hypothesis is rejected at significant level $\alpha$, at least one or more independent variable affects significantly dependent variables. In addition, 
a significant verification of partial coefficient $\left(\beta_{j}\right)$ was done by t-test. If a null hypothesis $\left(H_{0}: \beta_{j}=0\right)$ is rejected at significant level $\alpha$, it is determined that the independent variable $X_{j}$ affects significantly dependent variable $Y$.

Although factors to affect CDP are determined by mutually direct or indirect effect, survey of total contents is not only difficult in terms of time and cost, but becomes difficult of model estimation to occur multicollinearity problems among independent variables (Kim 2016b). Therefore, it is necessary to be appropriate selection of independent variable to have high explanatory power for CDP.

Multicollinearity indicates when a regressor $X_{i}$ (independent variable) is nearly a linear combination of other regressors $X_{k}$ in the model, where $X_{1}, X_{2}, \cdots, X_{p}$ are in the relationship of $\beta_{0}+\beta_{1} X_{1}+\beta_{2} X_{2}+\cdots+\beta_{p} X_{p} \cong 0$. At this time, at least two of $\beta_{1}, \beta_{2}, \cdots, \beta_{p}$ are not 0 . If there are multiple collinearities, the variance of the estimated value of some regression coefficients becomes excessively large and the estimated value of the regression coefficient becomes very unstable. In such a case, although coefficient value of determination $R^{2}$ is generally displayed large, most regression coefficients do not appear to be significant. Therefore, it is necessary to find out which variables are nearly collinear with other variables.

In this study, we employed variance inflation factor $(V I F)$ to confirm existence of multi-collinearity. VIF measures inflation in variances of the parameter estimations due to collinearities that exist among the regression (independent) variables. There are no formal criteria for decision whether a VIF is large enough to affect the predicted values (SAS 2009). The $V I F$ for the estimated $j^{\text {th }}$ predictor is described as $V I F_{j}=1 /\left(1-R_{j}^{2}\right)$. If the independent variable $X_{j}$ has no correlation with the remaining independent variables, then $R^{2}$ is $0, V I F_{j}$ become 1 . In other words, $V I F_{j}$ represents the inflation rate of variance for the regression coefficient according to the degree which the independent variable $X_{j}$ is explained by the remaining independent variables. Therefore, although it is likely that collinearity do not exist when $V I F_{j}$ is closer to 1 , if $V I F_{j}$ of regression coefficient is large, it is evaluated that there is multicollinearity.

In addition, a method to select an optimal independent variable in the model is the stepwise variable selection method (STEPWISE). A new variable in STEPWISE is obtained to be selected by additionally important variables via one by one for selecting a combination of the best described variable (Kim 2003). Model selection criteria are needed to select optimal variables in the model. The most commonly used criteria are coefficient of determination $\left(R^{2}\right)$, an adjusted coefficient of determination $\left(\overline{R^{2}}\right)$ and Mallows' total mean-squared error $\left(C_{p}\right)$. The $R^{2}$ statistic measures proportion of the total variation explained by the linear model. In models with intercept, it is defined as the ratio $R^{2}=1-S S R / S S T$, where SSE is the residual (error) sum of squares and SST is the total sum of squares corrected for the mean. $R^{2}$ is a value between 0 and 1 , and closer independent variable to 1 excellently explains dependent variable. The adjusted $R^{2}$ statistic is an alternative to $R^{2}$ that is adjusted for the number of parameter in the model. The adjusted $R^{2}$ statistic is calculated as $\overline{R^{2}}=1-\left[(n-i)\left(1-R^{2}\right)\right] /(n-p)$, where $n$ is the number of observations used in fitting the model, and $i$ is an indicator variable to become 1 if the model includes an intercept (SAS 2009). However, these statistics tend to be increased depending on addition of new variables.

In comparison, the $C_{p}$ statistic is proposed by Mallows (1973) as a criterion for selecting a model. It is a measure of totally squared error defined as $C_{p}=S S E_{p} / s^{2}-(N-2 p)$, where $s^{2}$ is MSE for the full model, and $S S E_{p}$ is the sum-of-square errors for a model with $p$ parameters including the intercept. If $C_{p}$ is plotted against $p$, Mallows recommends the model where $C_{p}$ first approaches $p$. When the right model is chosen, the parameter estimates are unbiased, and this is reflected in $C_{p}$ near $p$ (SAS 2009). $C_{p}$ statistic is used as a stopping rule for various forms of stepwise regression. Under a model no suffering from appreciable lack of fit (bias), $C_{p}$ has expectation nearly equal to $p$ which is the sum of intercept and independent numbers (Mallows 1973). With these criteria, Durbin-Watson statistic (DW) test shows that the autocorrelation is zero when regression is performed on time series data. The value of DW is close to 2 if the errors are uncorrelated (SAS 2009). Data were analyzed by PROC REG/CORR Procedure in SAS 9.2 (SAS 2009).

\section{Results and Discussion:-}

Examinations of coefficient for variation and amplification:-

Coefficient of variation (CV) is a standardized measurement for dispersion of a probability distribution or frequency distribution. It is often expressed as a percentage, and is defined as ratio of standard deviation to average. As the 
value of $\mathrm{CV}$ increases, the relative difference appears more greatly. Likewise, amplitude coefficient is a magnitude of difference between the highest and lowest values of variable over a period of time.

As shown in Table 2, domestic pork supply from 2003 to 2016 was decreased from 2003 to 2006, but increased from 2007. Although the supply decreased sharply in 2011 due to impact of foot- and -mouth disease occurred nationwide from the end of 2010 to March 2011, after the period, it increased again, and maintained a constant level of supply amount. The amplitude coefficient for the supply amount of pork was largely displayed in oscillation width of the supply amount with $46.7 \%$ at 2012 based on $19.1 \%$ of the total average. On the other hand, the average coefficient of variation was $8.1 \%$ on total average and maintained within $10 \%$ overall, but in 2011 and 2012, the coefficients were showed by fluctuation ranges of very high supply volumes throughout the years as $11.3 \%$ and $12.2 \%$, respectively. Therefore, annual average supply volume of domestically produced pork was evaluated to be largely influenced from external factors such as disease.

In addition, as pig production requires biological parallax from insemination to marketing, producer shows inelasticity of supply that does not respond instantly to change of price. Although consumption continues throughout the year, it shows seasonal fluctuations in which pork demand is significantly increased during the periods of the holiday season, lunar New Year's Day, and Korean Thanksgiving Day when compared to other seasons (Kim 2003). Especially, seasonal differences are observed in production and consumption of pork due to the four distinct seasons in South Korea (Kim, 2016a). Similarly, seasonality in the price and the demand and/or supply exists inherently in most agricultural commodity markets (Tomek and Peterson 2001).

\section{Multiple regression model by variance inflation factor:-}

We considered to affect domestic pork consumption and estimated regression model to use all the collected variables (Table 4). Although the convenience (bias) decreased when many independent variables are used in the model, since the multicollinearity among them increases and the variance increases, it is difficult to test the significance of the estimation coefficient (Kim 2003). Therefore, multiple collinearity by VIF was tested for the variables of the model. According to the results, the model was statistically significant $(\mathrm{p}<0.01)$, and $\overline{R^{2}}$ was very high as 0.979 . However, according to the t-test results of each regression coefficient, the estimates of the eight variables excluding domestic pork consumption (CDP), carried over amount (BSDP), inventory amount (ESDP) and export volume (EP) were not significant at a significance level of 5\%. Therefore, since collinearity existed between independent variables, it was evaluated that the estimated value of the regression coefficient is very unstable.

This evaluation was also confirmed by VIF for the estimated predictor (Table 3). FPDP, WPDP, PA15 and CPH of domestic pork were 97.96, 85.30, 16.02 and 13.71, which had high values of 10 or more. For example, since VIF for FPDP of predictive factor was highly correlated with any of the other predictors with FPDP, the variance of the estimation coefficient FPDP had increased to 97.96 times. Therefore, the problem of collinearity between variables is suspected in the model. As a result, we performed Pearson's correlation analysis and examined factors to maintain high correlation with other independent variables (Table 5).

According to analysis of correlation between variables, the domestic pork had high correlation coefficient value of 0.909 between BSDP and ESDP $(\mathrm{P}<0.01)$. Since supply amount of pork is sum of BSDP and PDP, BSDP and ESDP, the remaining parts post consumption from supply amount are defined to have property of demand function. FPDP, WPDP and CPDP of the domestic pork were highly correlated with each other $(\mathrm{P}<0.01)$. Therefore, WPDP was excluded from the further study. Since PA15 showed a high correlation with CPH, IP, PPF and CPC (P<0.01), it was excluded from the model. In addition, since PPF was displayed to no give special influence on pork price or production amount, but to have a great influence on CPH, CPC and PA15 $(\mathrm{P}<0.01)$, it was excluded from the model. Finally, according to the increases in export and import amounts of pork due to trade liberalization, IP and EP were introduced as explanatory variables, but EP excluded because it not only had little influence on PDP, but also had a considerable correlation with other explanatory variables. The slight influence of pork export in the domestic market was explained by the effect of the discontinuation of export by FMD which occurred in South Korea (Kim, 2016a; Oh and Whitley 2011). When compared with this, since IP had sharply increased after FTA came into effect, and occupied into an important amount in the domestic pork supply, it was adopted as the determinant factor of PDP.

In this way, a variable directly related to the research purpose was selected among the variables highly correlated with each other to reduce the collinearity between the independent variables of the model. In other words, the selected variables were directly related to PDP, but eliminated variables were indirectly related to it. As a result, 
CDP, BSDP, IP, WPDP, CPDP, CPH and CPC were selected as factors to determine PDP, and the regression model was again estimated by their factors (Table 5). The value of determination coefficient $\left(\overline{R^{2}}\right)$ was decreased from the original $97.9 \%$ to $81.3 \%$ depending on the fact that the number of variables in this way was reduced from 12 to 7 . However, although the number of independent variables was decreased, the estimate of the statistically significant parameter was increased from 4 to $5(\mathrm{P}<0.05)$. The estimated model was $81.3 \%$ of the total variance in the variance described by the regression, and at this time, the value was significant as $98.35(\mathrm{p}<0.01)$. In other words, $81.3 \%$ of the variation of the dependent variable (PDP) was explained by 7 independent variables chosen in the model. Although the explanatory power of the model lowered somewhat owing to decrease of $\overline{R^{2}}$, since it was not too big than 1 for each variable, there was a high possibility that collinearity does not exist (Table 6). WPDP was the most significant factor to affect PDP, and market price factors played an important role in determining production volume. As WPDP and PDP showed a negative relationship, when WPDP was increased, PDP was decreased $(\mathrm{P}<0.01)$. It is understood that lack of PDP induces price rise.

As CDP increases, the balance between market demand and supply maintain via increase of PDP $(\mathrm{P}<0.01)$. In addition, if domestic pork is large BSDP in the current month, since excess supply of pork may occur in the market, it is shown that the balance is adjusted by reducing PDP $(\mathrm{P}<0.01)$. Although IP of pork had not a significant impact on PDP, both factors showed a positive relationship $(\mathrm{P}<0.05)$. In addition, when $\mathrm{CPC}$ of poultry chosen as a substitute material rises, its demand decreases, but instead, PDP increases as the demand for pork increases $(\mathrm{P}<0.05)$. Furthermore, CPDP and CPH had the similar functions, but they were not statistically significant.

\section{Multiple regression model by stepwise selection method:-}

In this study, we selected the step-by-step variable selection method to another method for setting the optimum model while solving problem of multiple collinearity between independent variables. The variables to be included in the model were set to select a significant variable at level of 0.1 . As a result of addition of new variables and deletion of existing variables in 8 stages, we finally selected 4 independent variables of CDP, BSDP, ESDP and EP (Table 7). The results of factor analysis for PDP determination using four explanatory variables selected according to the choice of step variable were shown in Table 8 . The determination coefficient $\left(R^{2}\right)$ of the analysis model had a very high explanatory power of $97.8 \%$, and $C_{p}$ was 4.66 , which was analyzed to be slightly smaller than 5 of the combined value by 4 prediction variables and 1 constant term. The model showed to be relatively unbiased in estimating regression analysis coefficients and predicting future reactions.

According to the estimation result of the model, all the selected independent variables maintained a significant influence on PDP. The increased CDP also derived increase of PDP $(\mathrm{P}<0.01)$. This indicates the market principle that the market price rises according to increase of consumption and that producer and distributor to maximize profit increase production and market supply volumes. BSDP showed a negative relationship with PDP $(\mathrm{P}<0.01)$. Since sum of BSDP and PDP corresponds to the total supply of domestically produced pork in specific month, if BSDP increases, the pork supply amount in the domestic market exceeds the market demand. Therefore, since decline in price through the exceeded supply causes economic losses of producer and distributor, it is estimated that adjustment of market supply and demand balance is done by regulation of PDP.

On the other hand, in the model using VIF, as the correlation between ESDP and BSDP was a high value at 90.9\% $(\mathrm{P}<0.01)$, we judged that collinearity exists between the two variables. Therefore, BSDP was selected by excluding ESDP to have the nature of the demand function from the model. However, as the values of BSDP and ESDP were 7.78 and 8.66, respectively, the possibility of collinearity with other variables was large owing to further expansion of the variance of ESDP. ESDP was also chosen as the determinant factor of PDP for selecting the step variable. As a result, since ESDP and PDP had a positive relationship $(\mathrm{P}<0.01)$, it is estimated that the excessive increase in PDP causes oversupply in market and plays a role as a factor to increase ending stocks of domestic pork (ESDP). In addition, in Table 6, although domestically produced pork export volume (EP) was excluded from the model due to a small amount according to foot and mouth disease, PDP increased significantly if export volume (EP) was increased in stepwise selection method $(\mathrm{P}<0.01)$.

\section{Conclusions:-}

In this study, we investigated multicollinearity of factors influencing domestic pork production via application of time series data, and selected optimal independent variables to use the variance magnification factor and stepwise selection method, respectively. According to these results, CDP and BSDP commonly played an important roles for 
PDP. Since CDP displays demand for domestic pork market and BSDP indicates the market supply of domestically produced pork accompanied with PDP, both factors have been shown to play important roles based on the principle of supply and demand in the domestic pork market. In addition, Hanwoo beef and chicken, which are recognized as substitutes for pork in South Korea, were analyzed to play roles as a weak substitute materials. Since 2004, as conclusion and entry into effect of FTA have been expanded with advanced livestock countries, although the imported pork has occupied a large proportion of the total pork supply, the domestic pork export volume (EP) has presented an irregular disparity with PDP. Therefore, it is evaluated that EP cannot have a big influence on domestic pork supply. Domestic pork producer and distributor are necessary to build a supply system that responds to the occurrence of livestock diseases such as foot-and-mouth disease together with PDP and CPC. In addition, it needs to be noticed that production and consumption are determined by seasonally concentrated characteristics. In other words, although pig takes about 10 months from pig pregnancy to marketing, as the conception rate is low at the end of a muggy summer, the market supply volume decreased in early summer when the demand of the following year is high, whereas if breeding performs the winter season to maintain high conception rate, it is supplied in autumn when demand falls. As a result, there is an imbalance in market supply and demand.

Therefore, producer needs to focus on breeding, disease and rearing managements through understanding the biological characteristics of pig and the actual state of pork supply and demand in the market. In addition, distributor is important for increasing economic interests according to market characteristics such as adjusting the point of sale through safe and hygienic storage management. Sixth industrialization to build an integrated system that can carry out production, processing, distribution and sale of pork together can be a good way to contribute to the increase of social utility.

Table 1:- Supply function of domestic pork $(\mathrm{n}=166)$

\begin{tabular}{|l|c|c|c|}
\hline Variables & Mean \pm SD & Min. & Max. \\
\hline Production of domestic pork (PDP, ton) & $61554 \pm 7696$ & 37358 & 81029 \\
\hline Consumption of domestic pork (CDP, ton) & $60910 \pm 7877$ & 32680 & 76570 \\
\hline Beginning stocks of domestic pork (BSDP, ton) & $28690 \pm 8779$ & 11802 & 49286 \\
\hline Ending stocks of domestic pork (ESDP, ton) & $28603 \pm 8709$ & 11802 & 49286 \\
\hline Imports of pork (IP, ton) & $28827 \pm 10298$ & 9696 & 76102 \\
\hline Exports of pork (EP, ton) & $699.5 \pm 838$ & 3 & 4810 \\
\hline Population with age15 and above (PA15, thousand) & $40336 \pm 1899$ & 37161 & 43512 \\
\hline Farm Price of Domestic Pig (FPDP, a thousand KRW/110kg) & $327.6 \pm 66$ & 180.5 & 559.7 \\
\hline Average wholesale price of domestic pork (WPDP, KRW/kg) & $3987 \pm 803.2$ & 2226 & 6903 \\
\hline Average consumer price of domestic pork (CPDP, FRW/kg) & $16658 \pm 2404$ & 11616 & 23699 \\
\hline Average consumer price of Hanwoo beef (CPH, KRW/kg) & $30206 \pm 7631$ & 19475 & 44171 \\
\hline Average consumer price of chicken (CPC, KRW/kg) & $4757 \pm 866.9$ & 2573 & 6760 \\
\hline prices of pig feed (PPF, KRW/kg) & $516 \pm 73.7$ & 391.4 & 660.1 \\
\hline
\end{tabular}

References: Korean Statistical Information Service (http://kosis.kr), National Agricultural Cooperative Federation (https://livestock.nonghyup.com), Korea Meat Trade Association (http://kmta.or.kr)

Table 2:- Coefficient of the variation and amplification for production of pork

\begin{tabular}{|c|c|c|c|c|}
\hline Year & $\begin{array}{c}\text { Production of pork } \\
\text { (ton) }\end{array}$ & Standard deviation & $\begin{array}{c}\text { Coefficient of } \\
\text { variation (\%) }\end{array}$ & $\begin{array}{c}\text { Amplitude coefficient } \\
(\%)\end{array}$ \\
\hline 2003 & 63,227 & $3,719.0$ & 5.9 & 8.0 \\
\hline 2004 & 62,357 & $4,620.9$ & 7.4 & 16.6 \\
\hline 2005 & 60,514 & $3,677.2$ & 6.1 & 17.9 \\
\hline 2006 & 55,478 & $4,715.6$ & 8.5 & 20.3 \\
\hline 2007 & 58,015 & $4,608.1$ & 7.9 & 21.4 \\
\hline 2008 & 59,233 & $5,333.5$ & 9.0 & 10.1 \\
\hline 2009 & 59,896 & $3,616.4$ & 6.0 & 20.8 \\
\hline 2010 & 62,862 & $4,155.3$ & 6.6 & 10.7 \\
\hline 2011 & 46,491 & $5,253.0$ & 11.3 & 21.7 \\
\hline 2012 & 60,370 & $7,379.9$ & 12.2 & 46.7 \\
\hline 2013 & 69,371 & $6,579.2$ & 9.5 & 16.6 \\
\hline
\end{tabular}




\begin{tabular}{|c|c|c|c|c|}
\hline 2014 & 67,463 & $4,839.9$ & 7.2 & 17.0 \\
\hline 2015 & 68,398 & $6,322.3$ & 9.2 & 15.5 \\
\hline 2016 & 69,388 & $4,753.9$ & 6.9 & 23.9 \\
\hline Average & 61,647 & $4,969.6$ & 8.1 & 19.1 \\
\hline
\end{tabular}

Table 3:- Average monthly price and production of pork ${ }^{1)}$

\begin{tabular}{|c|c|c|c|c|c|c|}
\hline Month & January & February & March & April & May & June \\
\hline Price $(\mathrm{KRW} / \mathrm{kg})^{1)}$ & 306.0 & 304.8 & 316.6 & 327.0 & 355.3 & 385.1 \\
\hline Consumption (ton) & $63,824.7$ & $58,247.6$ & $64,753.3$ & $62,119.1$ & $59,279.8$ & $56,083.6$ \\
\hline Month & July & August & September & October & November & December \\
\hline Price $(\mathrm{KRW} / \mathrm{kg})^{1)}$ & 356.9 & 351.5 & 324.8 & 278.5 & 308.2 & 294.2 \\
\hline Consumption (ton) & $57,418.0$ & $59,254.0$ & $59,378.7$ & $67,317.9$ & $66,750.8$ & $64,825.2$ \\
\hline
\end{tabular}

${ }^{1)}$ Nominal price

Table 4:- Parameter estimates and VIF for the supply function of pork by corrected all data ${ }^{1)}$

\begin{tabular}{|l|c|c|c|c|c|}
\hline \multicolumn{1}{|c|}{ Variable } & Estimate & Std. Error & $\mathrm{t}$ Value & $\operatorname{Pr}>|\mathrm{t}|$ & VIF \\
\hline Intercept & -9487.6 & 7544.4 & -1.26 & 0.2105 & 0.00 \\
\hline CDP & 0.966 & 0.020 & 49.14 & $<.0001$ & 2.91 \\
\hline BSDP & -0.987 & 0.029 & -34.26 & $<.0001$ & 7.78 \\
\hline ESDP & 0.963 & 0.031 & 31.42 & $<.0001$ & 8.66 \\
\hline IP $^{2}$ & -0.016 & 0.016 & -1.01 & 0.3147 & 3.36 \\
\hline EP $^{2)}$ & 0.687 & 0.161 & 4.27 & $<.0001$ & 2.22 \\
\hline PA15 & 0.295 & 0.191 & 1.54 & 0.1254 & 16.02 \\
\hline FPDP & -1.069 & 13.611 & -0.08 & 0.9375 & 97.96 \\
\hline WPDP & -0.164 & 1.043 & -0.16 & 0.8755 & 85.30 \\
\hline CPDP & -0.004 & 0.093 & -0.04 & 0.9666 & 6.04 \\
\hline CPH & 0.054 & 0.044 & 1.24 & 0.2177 & 13.71 \\
\hline CPC & 0.104 & 0.223 & 0.47 & 0.6413 & 4.55 \\
\hline PPF & 0.031 & 3.833 & 0.01 & 0.9937 & 9.70 \\
\hline
\end{tabular}

${ }^{1)}$ F Value: 587.2, $\mathrm{P}<0.0001, R^{2}: 0.979, \overline{R^{2}}: 0.977, \mathrm{DW}: 1.640$.

${ }^{2)}$ Customs clearance standard.

Table 5:- Correlation matrix for the demand function of pork ${ }^{1)}$

\begin{tabular}{|l|l|l|l|l|l|l|l|l|l|l|l|l|}
\hline & CDP & BSDP & ESDP & $\mathbb{P}^{*}$ & $\mathrm{EP}^{2}$ & PA15 & FPDP & WPDP & CPDP & CPH & CPC & PPF \\
\hline PDP & $0.875^{*}$ & $0.390^{*}$ & $0.489^{*}$ & -0.117 & -0.048 & $0.327^{*}$ & $-0.395^{*}$ & $-0.439^{*}$ & $-0.376^{*}$ & $-0.251^{*}$ & -0.042 & 0.042 \\
\hline CDP & & $0.541^{*}$ & $0.440^{*}$ & -0.126 & -0.062 & $0.346^{*}$ & $-0.302^{*}$ & $-0.344^{*}$ & $-0.357^{*}$ & $-0.288^{*}$ & -0.064 & 0.055 \\
\hline BSDP & & & $0.909^{*}$ & 0.159 & $-0.335^{*}$ & $0.535^{*}$ & 0.014 & -0.029 & -0.175 & $-0.430^{*}$ & $0.246^{*}$ & $0.255^{*}$ \\
\hline ESDP & & & & $0.218^{*}$ & $-0.400^{*}$ & $0.577^{*}$ & -0.027 & -0.074 & -0.167 & $-0.457^{*}$ & $0.315^{*}$ & $0.297^{*}$ \\
\hline$P^{1)}$ & & & & & $-0.557^{*}$ & $0.689^{*}$ & $0.602^{*}$ & $0.570^{*}$ & $0.606^{*}$ & $-0.498^{*}$ & $0.502^{*}$ & $0.441^{*}$ \\
\hline EPP $^{1)}$ & & & & & & $-0.666^{*}$ & $-0.443^{*}$ & $-0.400^{*}$ & $-0.381^{*}$ & $0.555^{*}$ & $-0.646^{*}$ & $-0.562^{*}$ \\
\hline PA15 & & & & & & & $0.458^{*}$ & $0.376^{*}$ & $0.434^{*}$ & $-0.837^{*}$ & $0.652^{*}$ & $0.679^{*}$ \\
\hline FPDP & & & & & & & & $0.987^{*}$ & $0.795^{*}$ & $-0.328^{*}$ & $0.514^{*}$ & $0.448^{*}$ \\
\hline WPDP & & & & & & & & & $0.766^{*}$ & $-0.251^{*}$ & $0.475^{*}$ & $0.405^{*}$ \\
\hline CPDP & & & & & & & & & & $-0.225^{*}$ & $0.502^{*}$ & $0.402^{*}$ \\
\hline CPH & & & & & & & & & & & $-0.587^{*}$ & $-0.833^{*}$ \\
\hline CPC & & & & & & & & & & & & $0.787^{*}$ \\
\hline
\end{tabular}

"P<0.01.

1) CDP: consumption of domestic pork, PDP: production of domestic pork, BSDP: beginning stocks of domestic pork, IP: imports of pork, WPDP: average wholesale price of domestic pork, PA15: population with age 15 and above, ESDP: ending stocks of domestic pork, EP: exports of pork, CPDP: average consumer price of domestic pork, $\mathrm{CPH}$ : average consumer price of Hanwoo beef, and CPC: average consumer price of chickens.

${ }^{2)}$ Customs clearance standard. 
Table 6:- Parameter estimates and VIF for the supply function of pork by correlation analysis ${ }^{1)}$

\begin{tabular}{|l|c|c|c|c|c|}
\hline \multicolumn{1}{|c|}{ Variable } & Estimate & Std. Error & $\mathrm{t}$ Value & $\operatorname{Pr}>|\mathrm{t}|$ & $\mathrm{VIF}$ \\
\hline Intercept & 15837 & 5069.8 & 3.12 & 0.0021 & 0.00 \\
\hline CDP & 0.865 & 0.046 & 18.98 & $<.0001$ & 1.84 \\
\hline BSDP & -0.132 & 0.041 & -3.23 & 0.0015 & 1.84 \\
\hline IP $^{2}$ & 0.083 & 0.038 & 2.21 & 0.0285 & 2.15 \\
\hline WPDP & -2.214 & 0.543 & -4.08 & $<.0001$ & 2.72 \\
\hline CPDP & -0.127 & 0.199 & -0.64 & 0.5245 & 3.28 \\
\hline CPH & 0.001 & 0.051 & 0.02 & 0.9821 & 2.17 \\
\hline CPC & 1.122 & 0.442 & 2.54 & 0.0120 & 2.10 \\
\hline
\end{tabular}

${ }^{1)}$ F Value: $98.35, \mathrm{P}<0.0001, R^{2}: 0.813, \overline{R^{2}}: 0.805$, DW: 1.47.

${ }^{2)}$ Customs clearance standard.

Table 7:- Result of stepwise selection on independent variable for the supply function of pork ${ }^{1)}$

\begin{tabular}{|l|l|l|c|c|c|c|c|}
\hline Step & $\begin{array}{c}\text { Variable } \\
\text { Entered }\end{array}$ & $\begin{array}{c}\text { Variable } \\
\text { Removed }\end{array}$ & Partial $R^{2}$ & Model $R^{2}$ & $C_{p}$ & F-value & $\operatorname{Pr}>\mathrm{F}$ \\
\hline 1 & CDP & & 0.766 & 0.766 & 1526.02 & 535.43 & $<.0001$ \\
\hline 2 & WPDP & & 0.021 & 0.787 & 1373.78 & 16.39 & $<.0001$ \\
\hline 3 & PA15 & & 0.017 & 0.804 & 1252.67 & 14.14 & 0.0002 \\
\hline 4 & BSDP & & 0.019 & 0.823 & 1121.68 & 16.76 & $<.0001$ \\
\hline 5 & ESDP & & 0.153 & 0.975 & 24.81 & 983.29 & $<.0001$ \\
\hline 6 & EP & & 0.003 & 0.978 & 7.18 & 19.60 & $<.0001$ \\
\hline 7 & & PA15 & 0.000 & 0.978 & 5.38 & 0.19 & 0.6596 \\
\hline 8 & & WPDP & 0.000 & 0.978 & 4.66 & 1.29 & 0.2582 \\
\hline
\end{tabular}

${ }^{1)}$ No other variable met the 0.01 significance level for entry into the model.

Table 8:- Parameter estimates for the supply function of pork by stepwise selection ${ }^{1)}$

\begin{tabular}{|l|c|c|c|c|c|}
\hline Variable & DF & Estimate & Std. Error & $\mathrm{t}$-value & $\operatorname{Pr}>|\mathrm{t}|$ \\
\hline Intercept & 1 & 1635.2 & 743.7 & 2.20 & 0.0293 \\
\hline CDP & 1 & 0.984 & 0.014 & 70.67 & $<.0001$ \\
\hline BSDP & 1 & -1.005 & 0.027 & -37.52 & $<.0001$ \\
\hline ESDP & 1 & 0.989 & 0.026 & 38.12 & $<.0001$ \\
\hline EP & 1 & 0.720 & 0.119 & 6.04 & $<.0001$ \\
\hline
\end{tabular}

${ }^{1)}$ F Value: $1763.35, \mathrm{P}<0.0001, R^{2}: 0.978, \overline{R^{2}}: 0.977, C_{p}: 4.66$, DW: 1.61.

\section{Acknowledgements:-}

This research was supported by Priority Research Centers Program through the National Research Foundation of Korea (NRF) funded by the Ministry of Education (2009-0093813).

\section{References:-}

1. Davis, C.G., Lin B. (2005): "Factors Affecting U.S. Pork Consumption", Economic Research Service, LDP-M130-01, USDA.

2. FAOSTAT (2016): Live Animals, Food and Agriculture Organization of the United Nations (FAO). http://www.fao.org/faostat.

3. FAO (2014): FAO STATISTICAL YEARBOOK 2014: Asia and the Pacific Food and Agriculture, Food and Agriculture Organization of the United Nations Regional Office for Asia and the Pacific, Bangkok. pp. 96-98.

4. Kim T.W. (2003): A study on forecasting models of pig-farm price in Korea. Korean Journal of Agricultural Economics, 44: 43-66.

5. Kim T.W. (2016a): "Evaluation of determinant factors for entrepreneur- marketing stabilization of pork in South Korea by canonical correlation analysis". Int. J. Adv. Res., 4: 348-355.

6. Kim T.W. (2016b): "Determinants of the marketed-pig per sow per year for decision-making of piggery entrepreneur in South Korea". Int. J. Adv. Res., 4: 1301-1306.

7. Mallows C.L. (1973): "Some comments on Cp" Technometrics, 15: 661-675. 
8. SAS (2009): SAS/STAT 9.2 User's Guide 2nd. Cary, NC: SAS Institute Inc.

9. Thornton P.K. (2010): "Livestock production: recent trends, future prospects". Phil. Trans. R. Soc. B, 365: 2853-2867.

10. Tomek W.G., Peterson H.H. (2001): "Risk Management in Agricultural Markets: A Review". The Journal of Futures Markets, 21: 953-985.

11. Turner M.D., Williams T.O. (2002): "Livestock Market Dynamics and Local Vulnerabilities in the Sahel". World Development, 30: 683-705. 